\title{
Quality of life profile of general Vietnamese population using EQ-5D-5L
}

Long Hoang Nguyen ${ }^{1,2}$, Bach Xuan Tran ${ }^{2,3}$, Quynh Ngoc Hoang Le ${ }^{4}$, Tung Thanh Tran ${ }^{5^{*}}$ and Carl A. Latkin ${ }^{3}$

\begin{abstract}
Background: Health-related quality of life (HRQOL) is a vital benchmark to assess the effects of health interventions and policies. Measuring HRQOL of the general population is essential to establish a reference for health outcomes evaluations. However, evidence on HRQOL of general populations in low and middle income countries is very limited. This study aimed to measure HRQOL of the Vietnamese population by using the EuroQol- 5 dimensions- 5 levels (EQ-5D-5L) instrument and determine its associated factors.

Methods: A cross-sectional study was performed in Hanoi with 1571 residences in Hanoi, the capital city of Vietnam. EQ-5D-5L and EQ- visual analogue scale (EQ-VAS) were used to assess HRQOL. Potential covariates included socio-demographic characteristics, having acute symptoms in the last four weeks, chronic diseases in the last three months, having multiple health issues, and health service utilisation in the last twelve months. A generalized linear model was employed to identify the association between HRQOL and covariates.

Results: Overall, the mean EQ-5D utility index was 0.91 ( $S D=0.15$ ), and the mean EQ-VAS score was 87.4 $(\mathrm{SD}=14.3)$. The highest proportion of respondents reporting any problems was in Usual activities (24.3\%), followed by Anxiety/Depression (15.2\%) and Pain/Discomfort (10.0\%), while the lowest percentage was in Self-care (2.5\%). Lower HRQOL composite scores were related to unemployment, lower income, higher education, living in urban areas, having chronic diseases, having multiple health issues and using health service. For any health problem self-reported by respondents, the health utility reduced by 0.02 (respiratory diseases) to 0.15 (musculoskeletal diseases).
\end{abstract}

Conclusions: Health utility of the general population and reductions for self-reported health problems in this study are useful for future population health evaluations and comparisons. It also informs the development of interventions to reduce health problems of the general population.

Keywords: EQ-5D-5L, Health-related quality of life, Population, Norms, Vietnam

\section{Background}

Self-reported health-related quality of life (HRQOL) is commonly used for monitoring the health status of the general population and inform the effectiveness of treatments or health care policies [1, 2]. Evaluating the HRQOL of the general population can enable to compare the health status of the general population and specific patient groups to estimate the burden of different diseases as regards HRQOL [3]. In economic evaluations, HRQOL of the general population can play a role as a reference group to assess the incremental effectiveness of interventions if the control groups do not exist

\footnotetext{
* Correspondence: trantung94.hmu@gmail.com

5 Institute for Global Health Innovations, Duy Tan University, Da Nang,

Vietnam

Full list of author information is available at the end of the article
}

[4]. Moreover, in the realm of policy development, these HRQOL data can be used to support policy makers identifying policy gaps and inequalities for fulfilling, and detecting priorities to allocate resources $[5,6]$. Therefore, assessing HRQOL of the general population to construct population norms is becoming a necessity for the development of healthcare in each country.

Nonetheless, HRQOL itself does not reflect the clinically important differences in the treatments or policies directly. A term "minimal clinical important difference" (MCID) has been raised to provide such information. Beyond statistical significance, this term refers to the change of outcome that is large enough to be beneficial for the patients; and is worthy for patients to repeat the intervention or treatment if they have an opportunity to 
take again [7-9]. Methods to measure MCID can be classified into two groups: anchor-based and distribution-based [10]. The distribution-based used statistical features of the sample namely 0.5 standard deviation (0.5SD), effect size and one standard error of measurement (1SEM) as thresholds to detect clinical differences [10]. Meanwhile, anchor-based methods employ external indicators such as self-reported health outcomes and biological measurements [11]. Of which, health-related quality of life (HRQOL) has been broadly used to evaluate the MCID because it reflects the perceptions of patients about their physical and mental health and what the values of HRQOL are meaningful for them [8].

Previously, a general preference-based measure socalled EuroQol- 5 Dimensions - 3 Levels (EQ-5D-3L) was widely used to estimate health utility and HRQOL [4]. This tool describes the health status of respondents in five dimensions: mobility, self-care, usual activities, pain/discomfort and anxiety/depression, with three options to respond: no problem, moderate problems and severe problems [12]. However, its high ceiling effect becomes a major drawback that limits capacities to capture clinical differences regarding HRQOL [13]. A new instrument entitled EQ-5D-5 L, with five levels of response, is then introduced to replace EQ-5D-3 L. It has been proven that can reduce the ceiling effect and have high convergent validity, more sensitivity and is feasible to use in both clinical and community settings [14-19].

Due to the social and cultural differences, EQ-5D-5 L population norms have been reported and validated in many countries such as Spain [20], Australia [21], UK [16], Germany [17], Uruguay [14], Poland [22], Canada [23], and Japan [18]. Younger people, males, higher income, higher education, employed and married people were more likely to have better HRQOL $[14,16,18,21$, 22, 24, 25]. In Vietnam, EQ-5D-5 L has been employed to measure HRQOL among specific populations such as HIV positive patients [6,19], patients receiving methadone therapy [26-30], Vietnamese youths [31-33] and residences in mountainous settings [34]. However, there is none of the evidence on the HRQOL of general Vietnamese population. Therefore, this study aimed to profile the health status of general Vietnamese people living in Hanoi by using the EQ-5D-5 L instrument, and identify its associated factors.

\section{Methods}

\section{Study designs and participants}

A cross-sectional study was conducted in October 2015 in Hanoi, a capital of Vietnam. Hanoi is the biggest city of Vietnam with covering more than $3300 \mathrm{~km}^{2}$ and approximately 7.7 million people living in 30 districts and
584 communes until April 2017. The density of population is 2300 people $/ \mathrm{km}^{2}$ [35].

In this study, we selected randomly 176 communes in 29/30 districts as study settings. In each commune, we randomly selected ten people who had met following criteria: 1) Aged from 15 years old or above; 2) Agreeing to enroll in this study, and 3) Having ability to answer the survey. We approached eligible subjects, introduced about the research and invited them to participate in the study. People who accepted to enroll were asked to give written informed consent. A total of 1760 residents participated in the study; however, after excluding people who did not answer the EQ-5D-5 L instrument completely, the remaining sample size of this study was 1571 (89.3\%). No difference was found between included and excluded respondents in accordance with socioeconomic characteristics.

\section{Measures and instruments}

Face-to-face interviews were conducted by well-trained undergraduate and post-graduate students in the field of Public Health. We developed a structured questionnaire to collect data from respondents. The variables of interest were described as below:

\section{EQ-5D-5L}

In this study, HRQOL of participants was measured by using EuroQol-5 dimensions-5 levels (EQ-5D-5L). Five dimensions of this tool include Mobility, Self-care, Usual Activities, Pain/Discomfort and Anxiety/Depression, which have five levels of response: from no problems (code 1) to extreme problems (code 5). These levels of each dimension can be combined to identify 3125 possible health states from 11111 (full health) to 55555 (worst health) [36]. Each health state defines one single "utility" score, which can be transformed by using the interim scoring for EQ-5D-5 L. In the current study, due to the unavailability of Vietnamese cross-walk value set, we used the Thailand value set with the score ranged from -0.451 to 1 [36]. Moreover, another part of EQ$5 \mathrm{D}-5 \mathrm{~L}$ is a visual analogue scale (EQ-VAS), which can be used assesses the self-rated health of respondents by using a 100-mm scale with the score ranged from 0 (the worst health you can imagine) to 100 (the best health you can imagine). The Vietnamese version of EQ-5D-5 L has been used and validated in elsewhere [19].

\section{Other characteristics}

In this study, we collected socio-demographic characteristics of interest included age, living area, educational attainment, employment status, gender, total household income; and marital status. The household income was then separated into five quintiles from poorest to richest. We also asked participants to report whether they 
suffered acute symptoms in the last 4 weeks, having chronic diseases in the last 3 months and used health services in the last 12 months.

\section{Statistical analysis}

Data analysis was performed using Stata version 12.0 (Stata Corp. LP, College Station, United States of America). We described the socio-economic status, EQ-5D$5 \mathrm{~L}$ profiles, utility score and VAS scores according to age groups and gender. Due to the non-normal distribution of utility and VAS scores (Kolmogorov-Smirnov test, $p<0.05$ ), the differences of utility and VAS scores between different groups were tested by employing Mann-Whitney (for gender, living location, having acute symptoms in the past 4 weeks, having chronic diseases in the past 3 months and using health service in the past 12 months), and Kruska-wallis tests (for age groups, marital status, education, occupation, income quintiles, and number of health issues). Mann-whitney test was also used to test the differences of EQ-5D-5 L index and EQ-VAS score according to different dimensions of the EQ-5D-5 L instrument. Spearman's correlation coefficient was also conducted to identify the relationship between utility score and VAS score. Correlations were classified in three categories: weak $(\mathrm{rh} 0<0.3)$; moderate $(0.3<\mathrm{rh} 0<0.5)$; and strong $(>0.5)$ [37]. $P$-value $<0.05$ was considered statistical significance.

We detected the between-group MCID by using ANOVA test to compare the HRQOL of respondents with and without specific health conditions/diseases. The anchor-based approach has been argued that can be used in both cross-sectional and longitudinal designs $[18,38]$. In this study, we only included health conditions for which more than 10 participants had responded positively. This approach has been used in the previous study in Japan [18], which might assure to reliably detect the minimal differences of HRQOL between people with and without health conditions. However, we found that only the number of patients with hypertension met this criterion. Therefore, we decided to group the diseases into four categories: hypertension, respiratory diseases, musculoskeletal diseases and gastrointestinal diseases. Other categories such as cardiovascular diseases, endocrinology diseases, etc. did not have enough 10 respondents; thus, we did not include in the analysis.

Generalized linear model (GLM), which could manage skewness and heteroscedasticity, was employed to explore relationships between potential covariates and EQ$5 \mathrm{D}$ utility scores as well as VAS scores $[39,40]$. Due to the requirement of the model, because EQ-5D utility score may contain negative numbers, we computed the EQ-5D-5L disutility score (1-utility score) and used this score as a dependent variable in the model (model 1) [41]. Therefore, if the coefficient of one factor in the model is positive, it means that this factor can increase the disutility score; or decrease the utility score of EQ5D-5 L. We also divided EQ-VAS score to 100 and used the new variable as a dependent variable (model 2). Potential explanatory variables included age, living area, educational attainment, employment status, gender, household income quintiles (poorest to richest), marital status, having acute symptoms in the last 4 weeks, having chronic diseases in the last 3 months, number of health issues, and using health service in the last 12 months.

GLM models required accompanying distribution family and link function. Modified Park tests were used to determine data's distribution family based on the lowest $x^{2}$ values [41]. Three distribution families were tested including Gamma, Gaussian and Poisson, of which the Poisson family was the most appropriate family to describe the EQ-5D-5 L disutility and EQ-VAS score's distributions. In addition, we also identied the fitted link function for GLM models among three types (identity, squareroot and log links). By using Peason correlation test, Pregibon link test and Hosmer-Lemeshow test [40, 42], we found that the log was the most proper link function for the models. Theoretically, the log link function exponentiates the combination of predictors instead of log transforming the outcome data [41].

Reduced models were developed by using stepwise forward selection strategies, that variables were included based on the $p$-value $<0.1$ of the log-likelihood ratio tests [43].

\section{Results}

A total of 1571 individuals enrolled into the study. Most of the participants were female (61.5\%), adults aged from 25 to 44 (53.1\%), living with spouse/partner (65.5\%) and living in the urban area (86.0\%). The majority of respondents were at or having an undergraduate education $(52.5 \%)$. White-collars were predominant jobs with $31.3 \%$, followed by the Blue-collars (17.5\%) and students (16.7\%). Table 1 also shows that only $2.3 \%, 6.3 \%$ and 8.3\% respondents had acute symptoms in the last 4 weeks, chronic diseases in the last 3 months and had health issues, respectively. About one-fifth of participants utilized health care services in the last 12 months.

Fig. 1a illustrates that EQ-5D index was ranged from -0.452 to 1 , which was left-skewed with the dominant value at 1.00 (i.e. "Full health"). Similarly, Fig. 1b reveals that EQ-VAS score was ranged from 6 to 100, which was also left-skewed with the major clustering from 80 to 100 (i.e. "the best health you can imagine").

Table 2 depicts profiles of EQ-5D-5 L domains according to frequencies of each item response. The highest proportion of respondents reporting any problems was in Usual Activities (24.3\%), followed by Anxiety/ 
Table 1 Demographic characteristics of respondents

\begin{tabular}{|c|c|c|c|c|c|c|}
\hline \multirow[t]{2}{*}{ Characteristics } & \multicolumn{2}{|c|}{ Female } & \multicolumn{2}{|c|}{ Male } & \multicolumn{2}{|l|}{ Total } \\
\hline & $\mathrm{n}$ & $\%$ & $\mathrm{n}$ & $\%$ & $\mathrm{n}$ & $\%$ \\
\hline Total & 964 & 61.5 & 603 & 38.5 & 1567 & 100.0 \\
\hline \multicolumn{7}{|l|}{ Age groups } \\
\hline $15-24$ & 195 & 20.2 & 135 & 22.4 & 330 & 21.1 \\
\hline $25-34$ & 317 & 32.9 & 202 & 33.5 & 519 & 33.1 \\
\hline $35-44$ & 195 & 20.2 & 119 & 19.7 & 314 & 20.0 \\
\hline $45-54$ & 139 & 14.4 & 76 & 12.6 & 215 & 13.7 \\
\hline $55-64$ & 78 & 8.1 & 51 & 8.5 & 129 & 8.2 \\
\hline $65+$ & 40 & 4.2 & 20 & 3.3 & 60 & 3.8 \\
\hline \multicolumn{7}{|l|}{ Marital status } \\
\hline Single & 266 & 27.7 & 244 & 40.5 & 510 & 32.6 \\
\hline Live with spouse/partner & 677 & 70.4 & 347 & 57.6 & 1024 & 65.5 \\
\hline Divorce/Separate/Widow & 19 & 2.0 & 11 & 1.8 & 30 & 1.9 \\
\hline \multicolumn{7}{|l|}{ Education } \\
\hline Secondary school or less & 125 & 13.0 & 78 & 13.0 & 203 & 13.0 \\
\hline High school & 301 & 31.3 & 194 & 32.4 & 495 & 31.7 \\
\hline Undergraduate & 517 & 53.7 & 302 & 50.5 & 819 & 52.5 \\
\hline Postgraduate & 19 & 2.0 & 24 & 4.0 & 43 & 2.8 \\
\hline \multicolumn{7}{|l|}{ Occupation } \\
\hline Student & 161 & 16.7 & 100 & 16.6 & 261 & 16.7 \\
\hline Blue-collar & 127 & 13.2 & 147 & 24.4 & 274 & 17.5 \\
\hline White-collar & 315 & 32.7 & 175 & 29.1 & 490 & 31.3 \\
\hline Retired & 64 & 6.7 & 50 & 8.3 & 114 & 7.3 \\
\hline Housework & 197 & 20.5 & 13 & 2.2 & 210 & 13.4 \\
\hline Unemployed & 13 & 1.4 & 19 & 3.2 & 32 & 2.0 \\
\hline Others (freelancers, farmers, etc.) & 86 & 8.9 & 98 & 16.3 & 184 & 11.8 \\
\hline \multicolumn{7}{|l|}{ Living locations } \\
\hline Rural & 121 & 12.6 & 98 & 16.3 & 219 & 14.0 \\
\hline Urban & 843 & 87.5 & 505 & 83.8 & 1348 & 86.0 \\
\hline
\end{tabular}

Having acute symptoms in the past 4 weeks

$\begin{array}{lllllll}\text { Yes } & 28 & 2.9 & 8 & 1.3 & 36 & 2.3 \\ \text { No } & 936 & 97.1 & 592 & 98.7 & 1528 & 97.7\end{array}$

Having chronic diseases in the past 3 months

$\begin{array}{lllllll}\text { Yes } & 63 & 6.5 & 36 & 6.0 & 99 & 6.3 \\ \text { No } & 901 & 93.5 & 564 & 94.0 & 1465 & 93.7\end{array}$

Number of health issues

\begin{tabular}{lclllll}
0 & 878 & 91.1 & 558 & 92.7 & 1437 & 91.7 \\
1 & 78 & 8.1 & 42 & 7.0 & 120 & 7.7 \\
2 & 8 & 0.8 & 2 & 0.3 & 10 & 0.6 \\
Using health services in the past 12 months & & & & \\
Yes & 173 & 18.0 & 131 & 21.7 & 304 & 19.4 \\
No & 791 & 82.1 & 472 & 78.3 & 1263 & 80.6 \\
\hline
\end{tabular}

Depression (15.2\%) and Pain/Discomfort (10.0\%), while the lowest percentage was in Self-care (2.5\%).

The mean EQ-5D utility scores according to different characteristics of respondents were summarized in Table 3. Overall, the mean EQ-5D utility index was 0.91 $(\mathrm{SD}=0.15)$. Lower utility scores were observed in females, higher age groups, and lower income quintiles $(p<0.01)$. Participants who were divorced/separated/ widow had the lowest utility score (mean $=0.84$, $\mathrm{SD}=0.20)$ compared to other marital categories $(p<0.01)$. Additionally, people who were retired had a lower utility score (mean $=0.85, \mathrm{SD}=0.16$ ) in comparison to other people $(p<0.01)$. Similarly, people suffering chronic diseases or had any health issues had significantly lower utility scores than their counterparts $(p<0.05)$. Meanwhile, no statistically significant difference in utility scores was found regarding educational attainment, living location, having acute symptoms in the past 4 weeks and using health service in the past 12 months.

Table 4 provides summaries of the EQ-VAS score according to different socio-demographic characteristics. The mean EQ-VAS score was 87.4 $(\mathrm{SD}=14.3)$ with the statistically higher score in male compared to female. We also found significant differences on EQ-VAS scores in term of age groups, marital status, education attainment, occupation, living location, having acute and chronic diseases, having health issues, and using health care services $(p<0.01)$.

Table 5 shows that the EQ-VAS and EQ-5D- 5 L utility scores were varied significantly according to whether the respondents reported any problems or not in each dimension. Overall, regarding EQ-VAS, people having problem-free had 6 points higher than those who reported at least one problem; meanwhile, regarding EQ-5D-5 L utility score, respondents reporting at least one problem had 0.28 point lower than those not having any problems $(p<0.05)$.

Table 6 shows the between-group MCID in our sample. Regarding EQ-5D utility score, the significant MID $(p<0.05)$ were found between respondents with and without hypertension, musculoskeletal diseases, having chronic diseases in the last 3 months and having multiple health issues. Meanwhile, for EQ-VAS score, the significant MCID were found between respondents with and without respiratory diseases, musculoskeletal diseases, having acute symptoms in the last 4 weeks, having chronic diseases in the last 3 months and having multiple health issues.

Table 7 shows ten most common EQ-5D-5 L health states, which accounted for $93.8 \%$ of respondents. Health states "11111" (full health), "11112" (slightly problems in anxiety/depression) and "12111" (slightly problems in self-care) were the most frequent responses in the 

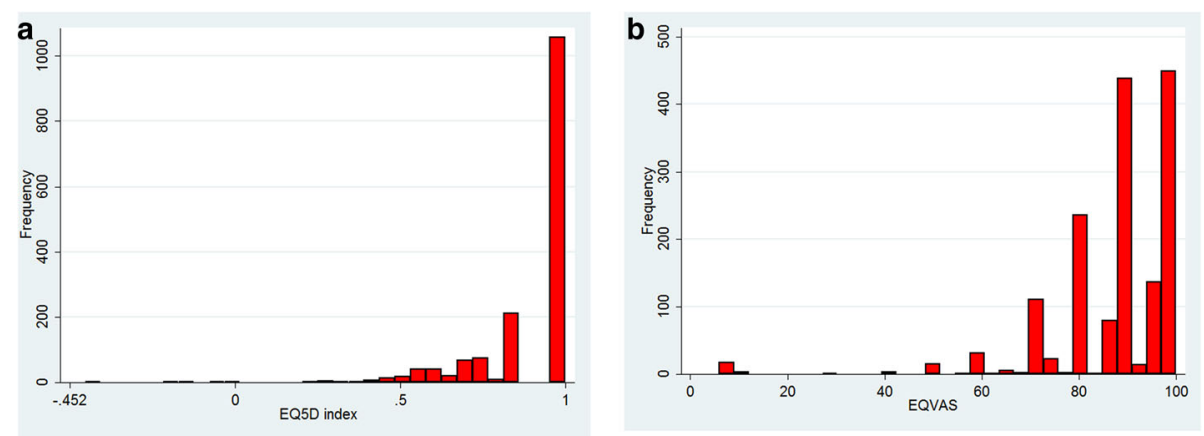

Fig. 1 Distribution of EQ5D index and EQVAS. a EQ5D index; b EQVAS

Table 2 Profiles of EQ-5D-5 L by age group

\begin{tabular}{|c|c|c|c|c|c|c|c|c|c|c|c|c|c|c|}
\hline \multirow[t]{2}{*}{ Domains } & \multicolumn{2}{|c|}{$15-24$} & \multicolumn{2}{|c|}{$25-34$} & \multicolumn{2}{|c|}{$35-44$} & \multicolumn{2}{|c|}{$45-54$} & \multicolumn{2}{|c|}{$55-64$} & \multicolumn{2}{|c|}{$65+$} & \multicolumn{2}{|l|}{ Total } \\
\hline & $\mathrm{n}$ & $\%$ & $\mathrm{n}$ & $\%$ & $\mathrm{n}$ & $\%$ & $n$ & $\%$ & $n$ & $\%$ & $\mathrm{n}$ & $\%$ & $\mathrm{n}$ & $\%$ \\
\hline \multicolumn{15}{|l|}{ Mobility } \\
\hline No problems & 317 & 96.1 & 501 & 96.2 & 302 & 95.9 & 198 & 92.1 & 118 & 91.5 & 50 & 82.0 & 1486 & 94.6 \\
\hline Slight problems & 10 & 3.0 & 14 & 2.7 & 13 & 4.1 & 14 & 6.5 & 9 & 7.0 & 9 & 14.8 & 69 & 4.4 \\
\hline Moderate problems & 3 & 0.9 & 3 & 0.6 & 0 & 0.0 & 2 & 0.9 & 2 & 1.6 & 1 & 1.6 & 11 & 0.7 \\
\hline Severe problems & 0 & 0.0 & 3 & 0.6 & 0 & 0.0 & 0 & 0.0 & 0 & 0.0 & 0 & 0.0 & 3 & 0.2 \\
\hline Unable to walk about & 0 & 0.0 & 0 & 0.0 & 0 & 0.0 & 1 & 0.5 & 0 & 0.0 & 1 & 1.6 & 2 & 0.1 \\
\hline \multicolumn{15}{|l|}{ Self-care } \\
\hline No problems & 323 & 97.9 & 514 & 98.7 & 309 & 98.1 & 208 & 96.7 & 123 & 95.4 & 54 & 88.5 & 1531 & 97.5 \\
\hline Slight problems & 5 & 1.5 & 4 & 0.8 & 5 & 1.6 & 4 & 1.9 & 6 & 4.7 & 6 & 9.8 & 30 & 1.9 \\
\hline Moderate problems & 0 & 0.0 & 1 & 0.2 & 1 & 0.3 & 2 & 0.9 & 0 & 0.0 & 0 & 0.0 & 4 & 0.3 \\
\hline Severe problems & 1 & 0.3 & 2 & 0.4 & 0 & 0.0 & 1 & 0.5 & 0 & 0.0 & 0 & 0.0 & 4 & 0.3 \\
\hline Extreme problems & 1 & 0.3 & 0 & 0.0 & 0 & 0.0 & 0 & 0.0 & 0 & 0.0 & 1 & 1.6 & 2 & 0.1 \\
\hline \multicolumn{15}{|l|}{ Usual activities } \\
\hline No problems & 259 & 78.5 & 409 & 78.5 & 236 & 74.9 & 164 & 76.3 & 87 & 67.4 & 34 & 55.7 & 1189 & 75.7 \\
\hline Slight problems & 67 & 20.3 & 108 & 20.7 & 79 & 25.1 & 49 & 22.8 & 40 & 31.0 & 23 & 37.7 & 366 & 23.3 \\
\hline Moderate problems & 2 & 0.6 & 3 & 0.6 & 0 & 0.0 & 2 & 0.9 & 2 & 1.6 & 3 & 4.9 & 12 & 0.8 \\
\hline Severe problems & 0 & 0.0 & 0 & 0.0 & 0 & 0.0 & 0 & 0.0 & 0 & 0.0 & 0 & 0.0 & 0 & 0.0 \\
\hline Unable to do & 2 & 0.6 & 1 & 0.2 & 0 & 0.0 & 0 & 0.0 & 0 & 0.0 & 1 & 1.6 & 4 & 0.3 \\
\hline \multicolumn{15}{|l|}{ Pain/Discomfort } \\
\hline No pain & 308 & 93.3 & 481 & 92.3 & 277 & 87.9 & 193 & 89.8 & 104 & 80.6 & 51 & 83.6 & 1414 & 90.0 \\
\hline Slight pain & 19 & 5.8 & 37 & 7.1 & 34 & 10.8 & 14 & 6.5 & 24 & 18.6 & 6 & 9.8 & 134 & 8.5 \\
\hline Moderate pain & 1 & 0.3 & 2 & 0.4 & 4 & 1.3 & 6 & 2.8 & 1 & 0.8 & 2 & 3.3 & 16 & 1.0 \\
\hline Severe pain & 2 & 0.6 & 1 & 0.2 & 0 & 0.0 & 0 & 0.0 & 0 & 0.0 & 0 & 0.0 & 3 & 0.2 \\
\hline Extreme pain & 0 & 0.0 & 0 & 0.0 & 0 & 0.0 & 2 & 0.9 & 0 & 0.0 & 2 & 3.3 & 4 & 0.3 \\
\hline \multicolumn{15}{|l|}{ Anxiety/Depression } \\
\hline Not anxious/depressed & 284 & 86.1 & 455 & 87.3 & 254 & 80.6 & 183 & 85.1 & 107 & 83.0 & 49 & 80.3 & 1332 & 84.8 \\
\hline Slightly & 34 & 10.3 & 59 & 11.3 & 54 & 17.1 & 25 & 11.6 & 20 & 15.5 & 8 & 13.1 & 200 & 12.7 \\
\hline Moderately & 10 & 3.0 & 5 & 1.0 & 5 & 1.6 & 4 & 1.9 & 2 & 1.6 & 1 & 1.6 & 27 & 1.7 \\
\hline Severely & 1 & 0.3 & 1 & 0.2 & 1 & 0.3 & 1 & 0.5 & 0 & 0.0 & 2 & 3.3 & 6 & 0.4 \\
\hline Extremely & 1 & 0.3 & 1 & 0.2 & 1 & 0.3 & 2 & 0.9 & 0 & 0.0 & 1 & 1.6 & 6 & 0.4 \\
\hline
\end{tabular}


Table 3 EQ-5D-5L utility scores by different characteristics

\begin{tabular}{|c|c|c|c|c|c|c|c|}
\hline & \multicolumn{3}{|l|}{ Total } & \multicolumn{2}{|c|}{ Female } & \multicolumn{2}{|l|}{ Male } \\
\hline & Mean & SD & $p$-value & Mean & SD & Mean & SD \\
\hline Total & 0.91 & 0.15 & & $0.91^{\mathrm{a}}$ & 0.14 & 0.92 & 0.15 \\
\hline \multicolumn{8}{|l|}{ Age groups } \\
\hline $15-24$ & 0.92 & 0.14 & $<0.01$ & 0.92 & 0.14 & 0.92 & 0.15 \\
\hline $25-34$ & 0.92 & 0.13 & & 0.92 & 0.14 & 0.94 & 0.12 \\
\hline $35-44$ & 0.91 & 0.14 & & 0.90 & 0.14 & 0.91 & 0.14 \\
\hline $45-54$ & 0.90 & 0.17 & & 0.90 & 0.16 & 0.90 & 0.20 \\
\hline $55-64$ & 0.88 & 0.16 & & 0.87 & 0.16 & 0.89 & 0.15 \\
\hline $65+$ & 0.81 & 0.25 & & 0.83 & 0.16 & 0.84 & 0.24 \\
\hline \multicolumn{8}{|l|}{ Marital status } \\
\hline Single & 0.92 & 0.15 & $<0.01$ & 0.92 & 0.14 & 0.93 & 0.15 \\
\hline Live with spouse/partner & 0.91 & 0.14 & & 0.90 & 0.14 & 0.91 & 0.14 \\
\hline Divorce/Separate/Widow & 0.84 & 0.20 & & 0.86 & 0.18 & 0.80 & 0.23 \\
\hline \multicolumn{8}{|l|}{ Education } \\
\hline Secondary school or less & 0.90 & 0.16 & 0.91 & 0.89 & 0.16 & 0.92 & 0.16 \\
\hline High school & 0.91 & 0.14 & & 0.90 & 0.15 & 0.93 & 0.14 \\
\hline Undergraduate & 0.91 & 0.14 & & 0.91 & 0.14 & 0.91 & 0.15 \\
\hline Postgraduate & 0.90 & 0.15 & & 0.89 & 0.16 & 0.90 & 0.14 \\
\hline \multicolumn{8}{|l|}{ Occupation } \\
\hline Student & 0.90 & 0.15 & $<0.01$ & 0.90 & 0.16 & 0.90 & 0.16 \\
\hline Blue-collar & 0.93 & 0.14 & & 0.91 & 0.14 & 0.94 & 0.13 \\
\hline White-collar & 0.92 & 0.14 & & 0.92 & 0.13 & 0.93 & 0.15 \\
\hline Retired & 0.85 & 0.16 & & 0.86 & 0.16 & 0.85 & 0.17 \\
\hline Housework & 0.88 & 0.16 & & 0.88 & 0.16 & 0.84 & 0.18 \\
\hline Unemployed & 0.89 & 0.18 & & 0.88 & 0.18 & 0.90 & 0.18 \\
\hline Others (freelancers, farmers, etc.) & 0.94 & 0.12 & & 0.94 & 0.11 & 0.94 & 0.14 \\
\hline \multicolumn{8}{|l|}{ Income quintiles } \\
\hline Poorest & 0.88 & 0.17 & $<0.01$ & 0.88 & 0.17 & 0.89 & 0.16 \\
\hline Poor & 0.90 & 0.15 & & 0.89 & 0.14 & 0.91 & 0.17 \\
\hline Middle & 0.92 & 0.14 & & 0.91 & 0.14 & 0.92 & 0.13 \\
\hline Rich & 0.93 & 0.11 & & 0.94 & 0.10 & 0.93 & 0.12 \\
\hline Richest & 0.94 & 0.15 & & 0.94 & 0.10 & 0.94 & 0.17 \\
\hline \multicolumn{8}{|l|}{ Living locations } \\
\hline Rural & 0.91 & 0.13 & 0.89 & 0.89 & 0.15 & 0.94 & 0.11 \\
\hline Urban & 0.91 & 0.15 & & 0.91 & 0.14 & 0.91 & 0.16 \\
\hline \multicolumn{8}{|c|}{ Having acute symptoms in the past 4 weeks } \\
\hline Yes & 0.87 & 0.17 & 0.09 & 0.85 & 0.18 & 0.94 & 0.10 \\
\hline No & 0.91 & 0.15 & & 0.91 & 0.14 & 0.92 & 0.15 \\
\hline \multicolumn{8}{|c|}{ Having chronic diseases in the past 3 months } \\
\hline Yes & 0.83 & 0.19 & $<0.01$ & 0.82 & 0.18 & 0.83 & 0.20 \\
\hline No & 0.91 & 0.15 & & 0.91 & 0.14 & 0.92 & 0.14 \\
\hline \multicolumn{8}{|l|}{ Number of health issues } \\
\hline 0 & 0.92 & 0.15 & $<0.01$ & 0.91 & 0.14 & 0.92 & 0.14 \\
\hline 1 & 0.85 & 0.18 & & 0.85 & 0.17 & 0.84 & 0.19 \\
\hline
\end{tabular}


Table 3 EQ-5D-5L utility scores by different characteristics (Continued)

\begin{tabular}{|c|c|c|c|c|c|c|c|}
\hline & \multicolumn{3}{|l|}{ Total } & \multicolumn{2}{|c|}{ Female } & \multicolumn{2}{|l|}{ Male } \\
\hline & Mean & SD & $\overline{p \text {-value }}$ & $\overline{\text { Mean }}$ & $\mathrm{SD}$ & Mean & SD \\
\hline 2 & 0.78 & 0.25 & & 0.72 & 0.25 & $1.00^{\mathrm{b}}$ & 0.00 \\
\hline \multicolumn{8}{|c|}{ Using health services in the past 12 months } \\
\hline Yes & 0.91 & 0.15 & 0.07 & 0.91 & 0.14 & 0.92 & 0.14 \\
\hline No & 0.89 & 0.16 & & 0.89 & 0.16 & 0.91 & 0.16 \\
\hline
\end{tabular}

${ }^{a} p$-value $=0.03$ (Mann-Whitney test): compare the difference of utility score between male and female

${ }^{b}$ There are only two males in this category

sample. However, we only found a low and positive correlation between utility scores and EQ-VAS scores $($ rh0 $=0.2850, p<0.01)$.

In the reduced multivariate generalized linear models, the EQ-5D-5 L disutility scores were found higher among those retired or having housework, having higher education, being at lower income quintiles and having chronic diseases in the last 3 months. Meanwhile, living in urban area, having chronic diseases, having a higher number of health issues, and utilizing health care services were negatively associated with the EQ-VAS score. Nevertheless, people who were at middle-income quintile, having full/part-time jobs or being a student were found to have better health status regarding EQ-VAS (Table 8).

\section{Discussion}

In our knowledge, this is the first study that offers critical insights into HRQOL of Vietnamese people, informing evidence for monitoring changes in health strategies and evaluating the effectiveness of public health intervention in the future. Generally, the mean EQ-5D utility score in our sample was $0.91(\mathrm{SD}=0.15)$, which was consistent with the utility scores of different populations worldwide measured by EQ-5D-5 L such as populations in Australian (0.90) [21]; German (0.92) [17]; Italian (0.92) [44], but lower than that of Uruguayan (0.95) [14] and Polish (0.96) [22]. The differences may be explained due to the difference of cross-walk value set used as well as cultural and social distinctions $[15,45,46]$. Notably, using the cross-walk value from Thailand instead of Vietnam is a major disadvantage of this study; however, the value set of Vietnamese preference is not available currently. Guidelines emphasized the need of having a specific value set for each country due to the cultural differences $[21,36]$. Therefore, in order to estimate HRQOL of Vietnamese people precisely, a direct measure of the value set for Vietnamese people is recommended and should be warranted in further studies.

In this study, we found that our sample had greater problems in usual activities and anxiety/depression (24.3\% and $15.2 \%$, respectively). This result was similar to a previous study in Vietnam, which used EQ-5D-3 L and showed that the percentage of people having anxiety/ depression was the highest [3]. In Australia, Germany, and Spain, the major problems were pain/ discomfort and mobility [20, 21], while in Poland, most of the respondents reported problems in pain/ discomfort and anxiety/depression. Noticeably, most of our sample (67.4\%) reported the perfect health state (11111). Although this figure indicates the benefit of EQ-5D-5 L in reducing ceiling effect compared to the previous data using EQ-5D-3 L (with $>85 \%$ reporting no problems in all dimensions) [3], the ceiling effect of this instrument remained strong. This result in our sample was similar to the result in Spanish population with 62.5\% [20], but it is much higher than in other countries such as Australia (42.8\%), UK (47.6\%), Germany (47.5\%), Uruguay (44.0\%), and Poland (38.5\%) [14, 17, 21, 22].

Meanwhile, only $22.8 \%$ people reported their VAS score at 100 points ("the best health state that you can imagine"), suggesting that the EQ-VAS is more proper than EQ-5D-5 L in measuring global health rating [16, 47]. Indeed, EQ-VAS has been used widely in monitoring the self-rated health of patients and populations over time along with biomedical and behavioral indicators [19, 28, 30, 47, 48]. EQ-VAS has good psychometric properties and is a simple tool to use. Further, this tool does not depend on any value sets [36]. However, EQVAS is less recommended to use in health economic evaluations than other direct preference-based measure namely time trade-off and standard gamble [49, 50]. Tran et al. in their systematic review argued that EQVAS might only reflect the alterations of perceptions of respondents rather than their real health status [51]. The authors suggested that EQ-VAS should be incorporated into other indirect preference-based measure such as EQ-5D-5 L to determine the short-term and long-term change of HRQOL more accurately [51]. As the correlation between EQ-5D utility score and the EQ-VAS score was low in this study, we confirmed the need for combining EQ-VAS and EQ-5D-5 L when conducting research in Vietnamese populations.

In the current study, we used the anchor-based approach by using the EQ-5D-5 L and EQ-VAS instruments to measure the between-group MCID between 
Table 4 EQ-VAS scores by different characteristics

\begin{tabular}{|c|c|c|c|c|c|c|c|}
\hline & \multicolumn{3}{|l|}{ Total } & \multicolumn{2}{|c|}{ Female $(n=964)$} & \multicolumn{2}{|c|}{ Male $(n=603)$} \\
\hline & Mean & SD & $p$-value & Mean & SD & $\overline{M e a n}$ & SD \\
\hline Total & 87.4 & 14.3 & & $87.1^{a}$ & 14.2 & 88.0 & 14.6 \\
\hline \multicolumn{8}{|l|}{ Age groups } \\
\hline $15-24$ & 88.5 & 15.8 & $<0.01$ & 87.1 & 18.0 & 90.5 & 11.6 \\
\hline $25-34$ & 88.1 & 14.5 & & 88.6 & 12.3 & 87.3 & 17.3 \\
\hline $35-44$ & 87.5 & 12.4 & & 87.2 & 12.6 & 88.1 & 12.1 \\
\hline $45-54$ & 85.8 & 15.0 & & 85.3 & 14.5 & 86.9 & 15.8 \\
\hline $55-64$ & 86.4 & 13.1 & & 85.8 & 13.5 & 87.4 & 12.6 \\
\hline $65+$ & 83.3 & 13.7 & & 82.6 & 12.3 & 83.9 & 16.3 \\
\hline \multicolumn{8}{|l|}{ Marital status } \\
\hline Single & 88.2 & 16.3 & $<0.01$ & 87.6 & 16.9 & 88.9 & 15.7 \\
\hline Live with spouse/partner & 87.2 & 13.1 & & 86.9 & 12.9 & 87.7 & 13.4 \\
\hline Divorce/Separate/Widow & 82.3 & 18.5 & & 85.3 & 16.2 & 77.3 & 21.8 \\
\hline \multicolumn{8}{|l|}{ Education } \\
\hline Secondary school or less & 86.3 & 12.3 & $<0.01$ & 85.1 & 12.2 & 88.2 & 12.3 \\
\hline High school & 87.2 & 13.4 & & 87.3 & 12.3 & 87.2 & 15.1 \\
\hline Undergraduate & 88.1 & 14.9 & & 87.5 & 15.5 & 89.2 & 13.9 \\
\hline Postgraduate & 83.5 & 20.1 & & 85.8 & 14.5 & 81.7 & 23.8 \\
\hline \multicolumn{8}{|l|}{ Occupation } \\
\hline Student & 88.0 & 16.0 & $<0.01$ & 86.4 & 18.4 & 90.6 & 10.6 \\
\hline Blue-collar & 88.0 & 12.9 & & 87.4 & 12.4 & 88.6 & 13.4 \\
\hline White-collar & 89.2 & 14.0 & & 88.7 & 13.4 & 90.1 & 15.0 \\
\hline Retired & 83.5 & 12.5 & & 84.5 & 11.4 & 82.7 & 13.8 \\
\hline Housework & 86.1 & 13.4 & & 86.5 & 12.4 & 79.7 & 23.4 \\
\hline Unemployed & 84.1 & 15.4 & & 86.2 & 11.6 & 82.7 & 17.7 \\
\hline Others (freelancers, farmers, etc.) & 85.6 & 16.0 & & 85.4 & 15.7 & 85.7 & 16.3 \\
\hline \multicolumn{8}{|l|}{ Income quintiles } \\
\hline Poorest & 86.4 & 13.3 & 0.24 & 86.2 & 13.6 & 86.9 & 12.9 \\
\hline Poor & 86.2 & 16.7 & & 86.1 & 17.1 & 86.6 & 16.1 \\
\hline Middle & 88.7 & 10.8 & & 88.2 & 11.4 & 89.8 & 9.3 \\
\hline Rich & 87.2 & 15.8 & & 88.2 & 10.3 & 85.9 & 21.0 \\
\hline Richest & 86.9 & 17.7 & & 86.6 & 17.7 & 87.1 & 17.7 \\
\hline \multicolumn{8}{|l|}{ Living locations } \\
\hline Rural & 90.2 & 10.0 & $<0.01$ & 88.5 & 10.9 & 92.2 & 8.4 \\
\hline Urban & 87.0 & 14.9 & & 86.9 & 14.6 & 87.2 & 15.4 \\
\hline \multicolumn{8}{|c|}{ Having acute symptoms in the last 4 weeks } \\
\hline Yes & 75.8 & 17.9 & $<0.01$ & 73.1 & 18.4 & 85.5 & 12.2 \\
\hline No & 87.7 & 14.1 & & 87.5 & 13.8 & 88.0 & 14.7 \\
\hline \multicolumn{8}{|c|}{ Having chronic diseases in the last 3 months } \\
\hline Yes & 78.1 & 18.5 & $<0.01$ & 79.8 & 15.1 & 75.0 & 23.1 \\
\hline No & 88.0 & 13.8 & & 87.6 & 14.0 & 88.8 & 13.6 \\
\hline \multicolumn{8}{|l|}{ Number of health issues } \\
\hline 0 & 88.3 & 13.6 & $<0.01$ & 87.9 & 13.7 & 88.9 & 13.6 \\
\hline 1 & 78.5 & 18.0 & & 79.4 & 15.6 & 76.7 & 21.9 \\
\hline
\end{tabular}


Table 4 EQ-VAS scores by different characteristics (Continued)

\begin{tabular}{|c|c|c|c|c|c|c|c|}
\hline & \multicolumn{3}{|l|}{ Total } & \multicolumn{2}{|c|}{ Female $(n=964)$} & \multicolumn{2}{|c|}{ Male $(n=603)$} \\
\hline & Mean & SD & $\overline{p \text {-value }}$ & Mean & SD & Mean & SD \\
\hline 2 & 70.5 & 17.1 & & 69.4 & 18.2 & 75.0 & 21.2 \\
\hline \multicolumn{8}{|c|}{ Using health services in the last 12 months } \\
\hline Yes & 82.3 & 19.2 & $<0.01$ & 82.1 & 18.7 & 82.5 & 20.0 \\
\hline No & 88.7 & 12.6 & & 88.2 & 12.7 & 89.6 & 12.3 \\
\hline
\end{tabular}

${ }^{\mathrm{a}} p$-value $=0.04$ (Mann-Whitney test): compare the difference of EQ-VAS score between male and female

participants with and without specific health conditions/ diseases. Generally, participants with any diseases, symptoms, and those people with increasing health issues had lower HRQOL. These findings were similar to the results from previous population-based surveys in Canada, Germany, and Japan [18, 52, 53]. The MCID of the EQ5D-5 L was 0.07 in people with one health issue and 0.14 in respondents with two health issues. These are consistent with the study in Canada, which indicated a decrease of 0.07 in people having one morbidity and 0.11 among those having two morbidities [52]. Notably, the results may be different from the intra-respondent MCID because the anchor-based method is commonly used in longitudinal studies, which measure the outcomes in multiple points of time. However, we aware that repeating surveys with a large sample size of the general population is burdensome. Moreover, the between-group MCID could

Table 5 EQ-5D-5L utility score and EQ-VAS score by different domains of EQ-5D-5 L instrument

\begin{tabular}{|c|c|c|c|c|c|c|}
\hline \multirow[t]{2}{*}{ Domain } & \multicolumn{3}{|c|}{ EQ-VAS score } & \multicolumn{3}{|c|}{ EQ-5D-5L utility score } \\
\hline & $\overline{\text { Mean }}$ & SD & $\overline{p \text {-value }}$ & $\overline{\text { Mean }}$ & SD & $p$-value \\
\hline \multicolumn{7}{|l|}{ Mobility } \\
\hline No problem & 88.2 & 13.8 & $<0.01$ & 0.93 & 0.11 & $<0.01$ \\
\hline Having problems & 74.3 & 16.7 & & 0.53 & 0.19 & \\
\hline \multicolumn{7}{|l|}{ Self-care } \\
\hline No problem & 87.8 & 14.0 & $<0.01$ & 0.92 & 0.12 & $<0.01$ \\
\hline Having problems & 71.5 & 19.3 & & 0.41 & 0.22 & \\
\hline \multicolumn{7}{|l|}{ Usual activities } \\
\hline No problem & 88.3 & 14.3 & $<0.01$ & 0.97 & 0.10 & $<0.01$ \\
\hline Having problems & 84.5 & 14.0 & & 0.71 & 0.14 & \\
\hline \multicolumn{7}{|l|}{ Pain/discomfort } \\
\hline No problem & 88.6 & 13.8 & $<0.01$ & 0.94 & 0.10 & $<0.01$ \\
\hline Having problems & 76.6 & 14.9 & & 0.61 & 0.17 & \\
\hline \multicolumn{7}{|l|}{ Anxiety/Depression } \\
\hline No problem & 88.8 & 13.9 & $<0.01$ & 0.95 & 0.10 & $<0.01$ \\
\hline Having problems & 79.6 & 14.5 & & 0.67 & 0.16 & \\
\hline \multicolumn{7}{|l|}{ All domains } \\
\hline Problem-free & 89.3 & 14.2 & $<0.01$ & 1.00 & 0.00 & $<0.01$ \\
\hline At least one problem & 83.5 & 13.8 & & 0.72 & 0.13 & \\
\hline
\end{tabular}

provide useful information with the appropriate intepretation [18]. Nonetheless, further understand about the MCID of each disease should be warranted in order to achieve optimal disease management.

Despite the significant differences in univariate analysis, multivariate models show that age, gender, and marital status were not associated with the HRQOL after adjusting for other variables. These results were different from priors studies, which indicated that elder groups, females, separate/divorce/widow people were more likely to have lower HRQOL than others [14, 16, 18, 21, 22, 24, 25]. Several reasons might be used to explain this phenonmenon. Statistically, in the multivariate analysis, we included factors that may covariate with age and gender such as number of health issues and having acute/chronic diseases, adjusting the associations between HQOL and those sociodemographic factors to be insignificant. Otherwise, the insignificant correlation between HRQOL and genders implies that males and females in Vietnam are equal at least on the HRQOL, which is perhaps a result of substantial efforts to improve the gender equality in Vietnam, particularly in health care access and utilization [54]. This is similar to the result in Sri Lanka [5] and Sweden [45]. Likewise, after controlling potential confounders, the likelihood of having better HRQOL is equal to all age groups. It can be due to the facts that in modern life, younger people may be increasingly exposed to diverse harmful factors such as stress, risk behaviors (smoking, alcohol use, opiate drug use or violence), negative interpersonal influences or isolation [31, 32, 55, 56]. Moreover, more and more adolescents and young adults suffer from some diseases such as overweight/ obesity and psychiatric disorders, which are rarely found in the elderly populations [57]. In the meantime, the older people, especially in urban areas, promote their independence/autonomy through increasing their social roles; engage in their social activities and have good physical and mental health due to the high quality of health care [58-60]. As a result, elder people can maintain their high HRQOL as the younger ones [58-60].

In this study, people with higher income and being employed had a higher likelihood to get better HRQOL, which was consistent with previous studies $[14,16,18$, $21,22,24,25]$. It could be explained that people having jobs and high income were more satisfied with their lives 
Table 6 Between-group MCID of EQ-VAS and EQ-5D utility scores for different health conditions

\begin{tabular}{|c|c|c|c|c|c|}
\hline \multirow[t]{2}{*}{ Health issue } & \multirow[t]{2}{*}{$\mathrm{n}$} & \multicolumn{2}{|c|}{ EQ-VAS score } & \multicolumn{2}{|c|}{ EQ-5D utility score } \\
\hline & & $\overline{\text { Diffa }^{a}}$ & $95 \% \mathrm{Cl}$ & $\overline{\text { Diffa }^{a}}$ & $95 \% \mathrm{Cl}$ \\
\hline Intercept & 1567 & 84.7 & & 0.91 & \\
\hline \multicolumn{6}{|l|}{ Common diseases } \\
\hline No diseases & 1437 & - & - & - & - \\
\hline Hypertension & 18 & -3.6 & $-10.3 ; 3.04$ & $-0.12^{*}$ & $-0.19 ;-0.05$ \\
\hline Respiratory diseases & 12 & $-18.6^{*}$ & $-26.7 ; 019.5$ & -0.02 & $-0.11 ; 0.07$ \\
\hline Musculoskeletal diseases & 31 & $-11.1^{*}$ & $-16.2 ;-6.0$ & $-0.15^{*}$ & $-0.20 ;-0.09$ \\
\hline Gastrointestinal diseases & 23 & -5.3 & $-11.2 ; 0.6$ & -0.04 & $-0.10 ; 0.02$ \\
\hline Having acute symptoms in the last 4 weeks & 36 & $-11.8^{*}$ & $-16.6 ;-7.1$ & -0.04 & $-0.09 ; 0.01$ \\
\hline Having chronic diseases in the last 3 months & 99 & $-10.0^{*}$ & $-12.8 ;-7.1$ & $-0.09^{*}$ & $-0.12 ;-0.06$ \\
\hline \multicolumn{6}{|l|}{ Number of health issues } \\
\hline 0 & 1437 & - & - & - & - \\
\hline 1 & 120 & $-9.8^{*}$ & $-13.0 ;-6.7$ & $-0.07^{*}$ & $-0.10 ;-0.04$ \\
\hline 2 & 10 & $-17.8^{*}$ & $-28.2 ;-7.3$ & $-0.14^{*}$ & $-0.25 ;-0.03$ \\
\hline
\end{tabular}

${ }^{\mathrm{a} D i f f e r e n c e ~ b e t w e e n ~ r e s p o n d e n t s ~ w i t h ~ a n d ~ w i t h o u t ~ h e a l t h ~ c o n d i t i o n s / d i s e a s e s ~}$ $* p<0.05$

and had higher chance to access health services. However, these findings also suggested the economic disparities in having good HRQOL, which might be more pressing in the future as the Vietnam Ministry of Health has a plan to significantly increase the fee of health services [61]. Moreover, respondents who were well-educated and urban residences were more likely to have a lower HRQOL, which persisted the prior findings in other countries [5, 20,21]. Several studies revealed that people with higher education and living in urban are more likely to suffer depression/ anxiety, which perhaps reduced their HRQOL [62-65]. Additionally, the multivariate analysis affirmed that people having health problems and using health services had a clinically significant reduction in HRQOL compared to their counterparts [26, 34].

This study implies several implications. First, the findings from this study could be used as reference figures,

Table 7 Most frequent EQ-5D-5 L health states with mean utility scores and EQVAS scores

\begin{tabular}{llllll}
\hline Health states & Number & Percent & Cum\% & Mean Utility & Mean VAS \\
\hline 11111 & 1058 & 67.4 & 67.4 & 1.00 & 89.3 \\
11112 & 211 & 13.4 & 80.8 & 0.79 & 89.6 \\
12111 & 54 & 3.4 & 84.2 & 0.81 & 81.4 \\
12112 & 45 & 2.9 & 87.1 & 0.73 & 86.1 \\
22111 & 34 & 2.2 & 89.2 & 0.72 & 83.6 \\
22112 & 24 & 1.5 & 90.8 & 0.67 & 82.2 \\
21112 & 15 & 1.0 & 91.7 & 0.70 & 81.7 \\
21111 & 11 & 0.7 & 92.4 & 0.78 & 82.7 \\
22222 & 11 & 0.7 & 93.1 & 0.47 & 75.0 \\
11212 & 10 & 0.6 & 93.8 & 0.66 & 68.5 \\
\hline
\end{tabular}

which can enable decision makers to identify the health care needs and burden of diseases; and monitor the effectiveness of policy alterations and provide future investments on health care. Clinicians can use these data to compare the health status of patients with specific conditions to the people with similar socio-economic characteristics [21, 22]. Likewise, the current findings can be used to compare health status among countries. Health economists can also use the data for comparing the difference of HRQOL between the general population and specific patient groups, which could help to calculate quality-adjusted life years in their economic evaluations in Vietnamese settings [40]. Second, offering employment opportunities for retired, unemployed or housework people; providing care promtply for people with illness and raising awareness of elder people about their social roles and promoting their engagement in social activities; and implementing educational interventions to change risk behaviors among young people are several approaches to enhance the HRQOL of the Vietnamese population. Notably, these interventions should not be distinguished between males and females because they are equally vulnerable to have low HRQOL. Finally, further studies to elicit the Vietnamese preference weights for EQ-5D utility index are needed to estimate the HRQOL of the Vietnamese population accurately.

The strength of this study is a large sample size to describe the health status of the general Vietnamese population. However, there are several limitations in our study. First, we only conducted this study in Hanoi, Vietnam; thus, the result may not represent the health status of the population in different settings. In addition, sick individuals may not be recruited into this study due 
Table 8 Generalized linear models of EQ-5D-5 L disutility scores, EQ-VAS scores, and different characteristics

\begin{tabular}{|c|c|c|c|c|}
\hline & \multicolumn{2}{|c|}{ EQ-5D-5L disutility score } & \multicolumn{2}{|c|}{ EQ-VAS scores } \\
\hline & Coef. & $95 \% \mathrm{Cl}$ & Coef. & $95 \% \mathrm{Cl}$ \\
\hline \multicolumn{5}{|l|}{ Age groups (vs 15-25) } \\
\hline $65+$ & $0.39^{*}$ & $-0.05 ; 0.84$ & & \\
\hline \multicolumn{5}{|l|}{ Occupation (vs Unemployed) } \\
\hline Full/part time, student & & & $0.17^{* *}$ & $0.00 ; 0.33$ \\
\hline Retired & $0.40^{* * *}$ & $0.08 ; 0.73$ & & \\
\hline Housework & $0.51^{* * *}$ & $0.25 ; 0.78$ & & \\
\hline \multicolumn{5}{|l|}{ Education (vs Secondary school or less) } \\
\hline$\geq$ Undergraduate & $0.27^{* * *}$ & $0.07 ; 047$ & & \\
\hline \multicolumn{5}{|l|}{ Income quintiles (vs Poorest) } \\
\hline Middle & $-0.24^{* *}$ & $-0.45 ;-0.03$ & $0.22^{* * *}$ & $0.08 ; 0.36$ \\
\hline Rich & $-0.50^{* * *}$ & $-0.83 ;-0.18$ & & \\
\hline Richest & $-0.52^{* * *}$ & $-0.88 ;-0.16$ & & \\
\hline Living locations (Urban vs Rural) & & & $-0.35^{* * *}$ & $-0.54 ;-0.15$ \\
\hline Having acute symptoms in the last four weeks (Yes vs No) & $0.38^{*}$ & $-0.07 ; 0.83$ & & \\
\hline Having chronic diseases in the last 3 months (Yes vs No) & $0.69^{* * *}$ & $0.39 ; 0.98$ & $-0.49^{* * *}$ & $-0.77 ;-0.21$ \\
\hline \multicolumn{5}{|l|}{ Number of health issues (vs No issue) } \\
\hline 1 & & & $-0.54^{* * *}$ & $-0.80 ;-0.27$ \\
\hline 2 & & & $-0.75^{* *}$ & $-1.34 ;-0.16$ \\
\hline Using health services in the last 12 months (Yes vs No) & & & $-0.38^{* * *}$ & $-0.59 ;-0.16$ \\
\hline Constant & $-2.49 * *$ & $-2.70 ;-2.29$ & $2.21^{* * *}$ & $1.99 ; 2.44$ \\
\hline $\mathrm{AlC}$ & 0.55 & & 1.91 & \\
\hline $\mathrm{BIC}$ & -9520 & & -9780 & \\
\hline
\end{tabular}

${ }^{*} p<0.1 ;{ }^{* *} p<0.05 ;{ }^{* * *} p<0.01$

to hospitalization or staying at home. Second, we used the cross-walk value set of Thailand population to derive the utility score of our sample instead of Vietnamese value set. Finally, the cross-sectional design used in this study may constrain the causal relations between HRQOL and other covariates.

\section{Conclusion}

The study informs the first evidence on the HRQOL of general Vietnamese population by using a well-validated instrument namely EQ-5D-5 L. The findings highlight that most of the respondents reported excellent health, and the major health problems were in usual activities and depression/ anxiety. Lower HRQOL were related to unemployed, lower income, higher education, living in urban areas, having acute and chronic diseases and using health service. Further studies should be elucidated to develop value set of Vietnamese population and apply this set to measure population norms.

\section{Abbreviation}

ANOVA: Analysis of variance; EQ-5D-5L: EuroQol - 5 dimensions - 5 levels; GLM: Generalized linear model; HIV: Human Immunodeficiency Virus; HRQOL: Health-related quality of life; MCID: Minimal clinical importance difference; SD: Standard deviation; SEM: Standard error of measurement; VAS: Visual analogue scale

\section{Acknowledgements}

The authors would like to acknowledge supports by the Hanoi Department of Health for the implementation of the study.

Funding

There was no funding for this analysis.

\section{Availability of data and materials}

The data that support the findings of this study are available from the Institute for Preventive Medicine and Public Health but restrictions apply to the availability of these data, which were used under license for the current study, and so are not publicly available. Data are however available from the authors upon reasonable request and with permission of the Institute for Preventive Medicine and Public Health.

\section{Authors' contributions}

LHN, BXT, TIT, CAL conceived of the study, and participated in its design and implementation and wrote the manuscript. LHN, BXT analyzed the data. All authors read and approved the final manuscript.

\section{Ethics approval and consent to participate}

The study protocol and ethical considerations were approved by the Institutional Review Board (IRB) of Hanoi Department of Health and the Institute for Preventive Medicine and Public Health. All participants received written informed consent after clear explanation. Respondents were allowed to withdraw from the interview at any time. All personal information was kept confidential and anonymous data were only utilized for the research. 


\section{Consent for publication}

Not applicable.

\section{Competing interests}

The authors declare that they have no competing interests.

\section{Publisher's Note}

Springer Nature remains neutral with regard to jurisdictional claims in published maps and institutional affiliations.

\section{Author details}

${ }^{1}$ School of Medicine and Pharmacy, Vietnam National University, Hanoi, Vietnam. ${ }^{2}$ Institute for Preventive Medicine and Public Health, Hanoi Medical University, Hanoi, Vietnam. ${ }^{3}$ Johns Hopkins Bloomberg School of Public Health, United States of America, Baltimore, MD, USA. ${ }^{4}$ Faculty of Pharmacy, Duy Tan University, Da Nang, Vietnam. ${ }^{5}$ Institute for Global Health Innovations, Duy Tan University, Da Nang, Vietnam.

\section{Received: 5 July 2017 Accepted: 27 September 2017}

\section{Published online: 11 October 2017}

\section{References}

1. Ravens-Sieberer U. Measuring and monitoring quality-of-life in population surveys: still a challenge for public health research. Soz Praventivmed. 2002;47:203-4

2. Kruk ME, Freedman LP. Assessing health system performance in developing countries: a review of the literature. Health Policy. 2008;85:263-76.

3. Tran BX, Ohinmaa A, Nguyen LT, Nguyen TA, Nguyen TH. Determinants of health-related quality of life in adults living with HIV in Vietnam. AIDS Care 2011;23:1236-45

4. Brazier J, Ratcliffe J, Tsuchiya A, Salomon JA. Measuring and Valuing Health Benefits for Economic Evaluation. Oxford, UK: Oxford University Press; 2016

5. Kularatna S, Whitty JA, Johnson NW, Jayasinghe R, Scuffham PA. EQ-5D-3L Derived Population Norms for Health Related Quality of Life in Sri Lanka. PLoS One. 2014;9:e108434

6. Tran BX, Hwang J, Nguyen LH, Nguyen AT, Latkin NRK, Tran NK, Minh Thuc $V T$, Nguyen HLT, Phan HTT, Le HT, et al. Impact of Socioeconomic Inequality on Access, Adherence, and Outcomes of Antiretroviral Treatment Services for People Living with HIV/AIDS in Vietnam. PLoS One. 2016;11:e0168687.

7. Cook CE. Clinimetrics Corner: The Minimal Clinically Important Change Score (MCID): A Necessary Pretense. J Man Manip Ther. 2008;16:E82-3.

8. Rai SK, Yazdany J, Fortin PR, Aviña-Zubieta JA. Approaches for estimating minimal clinically important differences in systemic lupus erythematosus. Arthritis Res Ther. 2015:17(1):143.

9. Copay AG, Subach BR, Glassman SD, Polly DW, Schuler TC. Understanding the minimum clinically important difference: a review of concepts and methods. Spine J. 2007;7:541-6.

10. Revicki D, Hays RD, Cella D, Sloan J. Recommended methods for determining responsiveness and minimally important differences for patient-reported outcomes. J Clin Epidemiol. 2008:61:102-9.

11. Revicki DA, Cella D, Hays RD, Sloan JA, Lenderking WR, Aaronson NK. Responsiveness and minimal important differences for patient reported outcomes. Health Qual Life Outcomes. 2006:4:70.

12. EQ-5D-3L User Guide. Basic information on how to use the EQ-5D-3L instrument. [https://euroqol.org/wp-content/uploads/2016/09/EQ-5D-3L_ UserGuide_2015.pdf]. Accessed 25 July 2017.

13. Herdman M, Gudex C, Lloyd A, Janssen M, Kind P, Parkin D, Bonsel G, Badia $X$. Development and preliminary testing of the new five-level version of EQ5D (EQ-5D-5L). Qual Life Res. 2011;20:1727-36.

14. Augustovski F, Rey-Ares L, Irazola V, Garay OU, Gianneo O, Fernandez G, Morales M, Gibbons L, Ramos-Goni JM. An EQ-5D-5L value set based on Uruguayan population preferences. Qual Life Res. 2016;25:323-33.

15. Brennan DS, Teusner DN. Comparing UK, USA and Australian values for EQ$5 \mathrm{D}$ as a health utility measure of oral health. Community Dent Health. 2015;32:180-4

16. Feng $Y$, Devlin $N$, Herdman M. Assessing the health of the general population in England: how do the three- and five-level versions of EQ-5D compare? Health Qual Life Outcomes. 2015:13:171.

17. Hinz A, Kohlmann T, Stobel-Richter $Y$, Zenger $M$, Brahler $E$. The quality of life questionnaire EQ-5D-5L: psychometric properties and normative values for the general German population. Qual Life Res. 2014;23:443-7.
18. Shiroiwa T, Fukuda T, Ikeda S, Igarashi A, Noto S, Saito S, Shimozuma K. Japanese population norms for preference-based measures: EQ-5D-3L, EQ5D-5L, and SF-6D. Qual Life Res. 2016;25:707-19.

19. Tran BX, Ohinmaa A, Nguyen LT. Quality of life profile and psychometric properties of the EQ-5D-5L in HIV/AIDS patients. Health Qual Life Outcomes. 2012;10:132.

20. Garcia-Gordillo MA, Adsuar JC, Olivares PR. Normative values of EQ-5D-5L: in a Spanish representative population sample from Spanish Health Survey, 2011. Qual Life Res. 2016;25:1313-21.

21. McCaffrey N, Kaambwa B, Currow DC, Ratcliffe J. Health-related quality of life measured using the EQ-5D-5L: South Australian population norms. Health Qual Life Outcomes. 2016;14:133.

22. Golicki D, Niewada M. EQ-5D-5L Polish population norms. Arch Med Sci. 2017;13:191-200.

23. Alberta HQCo: Alberta population norms for EQ-5D-5L. Alberta: Health Quality Council of Alberta; 2014.

24. Perneger TV, Combescure C, Courvoisier DS. General population reference values for the French version of the EuroQol EQ-5D health utility instrument. Value Health. 2010;13:631-5.

25. Sorensen J, Davidsen M, Gudex C, Pedersen KM, Bronnum-Hansen H. Danish EQ-5D population norms. Scand J Public Health. 2009;37:467-74.

26. Nguyen LH, Nguyen LHT, Boggiano VL, Hoang CD, Van Nguyen $H$, Le HT, Le HQ, Tran TD, Tran BX, Latkin CA, et al. Quality of life and healthcare service utilization among methadone maintenance patients in a mountainous area of Northern Vietnam. Health Qual Life Outcomes. 2017;15:77.

27. Nguyen LH, Tran BX, Nguyen HLT, Nguyen $C T$, Hoang CD, Le HQ, Van Nguyen H, Le HT, Tran TD, Latkin CA, TMT V. Psychological Distress Among Methadone Maintenance Patients in Vietnamese Mountainous Areas. AIDS Behav; 2017.

28. Tran BX, Nguyen LH, Nong VM, Nguyen CT, Phan HT, Latkin CA. Behavioral and quality-of-life outcomes in different service models for methadone maintenance treatment in Vietnam. Harm Reduct J. 2016:13:4.

29. Tran BXNL, Phan HT, Nguyen LK, Latkin CA. Preference of methadone maintenance patients for the integrative and decentralized service delivery models in Vietnam. Harm Reduction J. 2015;12(1):29.

30. Nguyen LH, Nguyen HTT, Nguyen HLT, Tran BX, Latkin CA. Adherence to methadone maintenance treatment and associated factors among patients in Vietnamese mountainside areas. Subst Abuse Treat Prev Policy. 2017:12:31.

31. Tran BX, Huong LT, Hinh ND, Nguyen LH, Le BN, Nong VM, Thuc VT, Tho TD, Latkin C, Zhang MW, Ho RC. A study on the influence of internet addiction and online interpersonal influences on health-related quality of life in young Vietnamese. BMC Public Health. 2017;17:138.

32. Zhang MWB, Tran BX, Huong LT, Hinh ND, Nguyen HLT, Tho TD, Latkin C, Ho RCM. Internet addiction and sleep quality among Vietnamese youths. Asian J Psychiatr. 2017;28:15-20.

33. Zhang MWB, Tran BX, Nguyen HLT, Le HT, Long NH, Le HT, Hinh ND, Tho TD, Le BN, Thuc VTM, et al. Using Online Respondent Driven Sampling for Vietnamese Youths' Alcohol Use and Associated Risk Factors. Healthc Inform Res. 2017:23:109-18.

34. Tran BX, Nguyen LH, Nong VM, Nguyen CT. Health status and health service utilization in remote and mountainous areas in Vietnam. Health Qual Life Outcomes. 2016;14:85.

35. Hanoi. [https://en.wikipedia.org/wiki/Hanoi]. Accessed 10 Sept 2017.

36. EQ-5D-5L User Guide. Basic information on how to use the EQ-5D-5L instrument [https://euroqol.org/wp-content/uploads/2016/09/EQ-5D-5L UserGuide_2015.pdf]. Accessed 25 July 2017.

37. Cohen J. The Significance of a product moment rs. In: Hillsdale JC, editor. Statistical power analysis for the behavioural sciences. New Jersey: Lawrence Erlbaum Associates; 1988.

38. Eton DT, Cella D, Yost KJ, Yount SE, Peterman AH, Neuberg DS, Sledge GW, Wood WC. A combination of distribution- and anchor-based approaches determined minimally important differences (MIDs) for four endpoints in a breast cancer scale. J Clin Epidemiol. 2004;57:898-910.

39. Mihaylova B, Briggs A, O'Hagan A, Thompson SG. Review of statistical methods for analysing healthcare resources and costs. Health Econ. 2011;20:897-916.

40. Glick HA, Doshi JA, Sonnad SS, Polsky D. Economic evaluation in clinical trials. Oxford: Oxford University Press; 2015.

41. Manning WG, Mullahy J. Estimating log models: to transform or not to transform? J Health Econ. 2001;20:461-94.

42. Starkie HJ, Briggs AH, Chambers MG, Jones P. Predicting EQ-5D Values Using the SGRQ. Value Health. 2011;14:354-60. 
43. David W. Hosmer, Lemeshow S: Applied Logistic Regression. 2nd ed. New York: Wiley; 2000

44. Scalone L, Cortesi PA, Ciampichini R, Cesana G, Mantovani LG. Health Related Quality of Life norm data of the Italian general population: results using the EQ-5D-3L and EQ-5D-5L instruments. Epidemiol Biostatistics Public Health. 2015;12:11451-15.

45. Burstrom K, Sun S, Gerdtham UG, Henriksson M, Johannesson M, Levin LA, Zethraeus N. Swedish experience-based value sets for EQ-5D health states. Qual Life Res. 2014;23:431-42.

46. Pullenayegum EM, Perampaladas K, Gaebel K, Doble B, Xie F. Betweencountry heterogeneity in EQ-5D-3L scoring algorithms: how much is due to differences in health state selection? Eur J Health Econ. 2015;16:847-55.

47. Feng Y, Parkin D, Devlin NJ. Assessing the performance of the EQ-VAS in the NHS PROMs programme. Qual Life Res. 2014;23:977-89.

48. Parkin D, Rice N, Devlin N. Statistical analysis of EQ-5D profiles: does the use of value sets bias inference? Med Decis Mak. 2010;30:556-65.

49. Health CAfDaTi. Guidelines for the economic evaluation of health technologies. Ottawa: Canadian Agency for Drugs and Technologies in Health; 2006.

50. Excellence $\mathrm{NIfHaC}$. Guide to the methods of technology appraisal 2013. UK: NHS; 2013.

51. Tran B, Nguyen L, Ohinmaa A, Maher R, Nong V, Latkin CA. Longitudinal and cross sectional assessments of health utility in adults with HIV/AIDS: a systematic review and meta-analysis. BMC Health Serv Res. 2015;15:7.

52. Agborsangaya CB, Lau D, Lahtinen M, Cooke T, Johnson JA. Health-related quality of life and healthcare utilization in multimorbidity: results of a crosssectional survey. Qual Life Res. 2013;22:791-9.

53. Huber MB, Felix J, Vogelmann M, Leidl R. Health-Related Quality of Life of the General German Population in 2015: Results from the EQ-5D-5L. Int J Environ Res Public Health. 2017;14.

54. Minister P. Decision 2351/QD-TTg, approving the National Strategy on Gender Equality for the 2011-2020 period. Hanoi: Vietnam Government; 2012.

55. Patton GC, Coffey C, Sawyer SM, Viner RM, Haller DM, Bose K, Vos T, Ferguson J, Mathers CD. Global patterns of mortality in young people: a systematic analysis of population health data. Lancet. 374:881-92.

56. Forouzanfar MH, Alexander L, Anderson HR, Bachman VF, Biryukov S, Brauer M, Burnett R, Casey D, Coates MM, Cohen A, et al. Global, regional, and national comparative risk assessment of 79 behavioural, environmental and occupational, and metabolic risks or clusters of risks in 188 countries, 19902013: a systematic analysis for the Global Burden of Disease Study 2013. Lancet. 2015;386:2287-323.

57. The Global Burden of Disease C, Adolescent Health C: Child and adolescent health from 1990 to 2015: Findings from the global burden of diseases, injuries, and risk factors 2015 study. JAMA Pediatr 2017, 171:573-592.

58. Bowling A. Quality of life in older age: what older people say. Dordrecht: Springer; 2007.

59. Van Nguyen $T$, Van Nguyen $H$, Duc Nguyen $T$, Van Nguyen $T$, The Nguyen T. Difference in quality of life and associated factors. J Prev Med Hyg. 2017; 58:E63-71.

60. Huong NT, Ha LTH, Tien TQ. Determinants of Health-Related Quality of Life Among Elderly: Evidence From Chi Linh Town, Vietnam. Asia Pac J Public Health. 2017;29(5_suppl):84S-93S.

61. Health Mo. Circular No. 02/2017/TT-BYT dated 15 th March 2017 of the Ministry of Health, stipulating the maximum levels in price list for medical examination and treatment services, which do not fall within the payment scope of Health Insurance Fund in the State-owned medical examination and treatment facilities and guidance on pricing and payment for medical examination and treatment in some cases. Hanoi: Ministry of Health; 2017.

62. Wittchen HU, Essau CA, von Zerssen D, Krieg JC, Zaudig M. Lifetime and sixmonth prevalence of mental disorders in the Munich Follow-Up Study. Eur Arch Psychiatry Clin Neurosci. 1992;241:247-58.

63. Muntaner C, Eaton WW, Diala C, Kessler RC, Sorlie PD. Social class, assets, organizational control and the prevalence of common groups of psychiatric disorders. Soc Sci Med. 1998;47:2043-53.

64. Lin M, Chen Y, McDowell I. Increased risk of depression in COPD patients with higher education and income. Chron Respir Dis. 2005;2:13-9.

65. Goering P, Lin E, Campbell D, Boyle MH, Offord DR. Psychiatric disability in Ontario. Can J Psychiatr. 1996;41:564-71.

\section{Submit your next manuscript to BioMed Central and we will help you at every step:}

- We accept pre-submission inquiries

- Our selector tool helps you to find the most relevant journal

- We provide round the clock customer support

- Convenient online submission

- Thorough peer review

- Inclusion in PubMed and all major indexing services

- Maximum visibility for your research

Submit your manuscript at www.biomedcentral.com/submit

) Biomed Central 